\author{
A. Kenneth J. Tardiff, ${ }^{1}$ M.D., M.P.H.; Zachary Wallace, ${ }^{2}$ Melissa Tracy,; Tinka Markham Piper, ${ }^{2}$ M.P.H.; \\ David Vlahov, ${ }^{2,3}$ Ph.D.; and Sandro Galea, ${ }^{2,3}$ M.D., Dr.P.H.
}

\title{
Drug and Alcohol Use as Determinants of New York City Homicide Trends From 1990 to 1998*
}

\begin{abstract}
In this population-level study, we analyzed how well changes in drug and alcohol use among homicide victims explained declining homicide rates in New York City between 1990 and 1998. Victim demographics, cause of death, and toxicology were obtained for all homicide $(N=12573)$ and accidental death victims $(N=6351)$ between 1990 and 1998 from the Office of the Chief Medical Examiner of New York (OCME). The proportion of homicide and accident decedents positive for cocaine fell between 1990 and 1998 (13\% and 9\% respectively); the proportion of homicide and accident decedents positive for opiates and/or alcohol did not change significantly. Changing patterns of drug and alcohol use by homicide victims were comparable to changing patterns of drug and alcohol use in accident victims, suggesting that changes in drug and alcohol use among homicide victims between 1990 and 1998 cannot solely explain the decline in NYC homicide rates.
\end{abstract}

KEYWORDS: forensic science, homicide, drug use, alcohol, epidemiology

Between 1990 and 1998, homicide rates declined in many cities across the United States (1). The number of homicides in New York City, for instance, fell $72 \%$ from an all time high of 2245 in 1990 to 633 in 1998 (2). Other cities that also witnessed decreasing homicide rates of two-thirds or greater during the 1990s included Boston, San Diego, and Los Angeles. In Chicago, Philadelphia, Phoenix, and Detroit, the decline in homicide was more modest with most reports approximating a one-third decline in homicide rates during the decade (2).

Several explanations have been suggested both for the high homicide rates in U.S. cities in the late 1980s and early 1990s and for the subsequent decline in homicide rates (3). One potential explanation is that changing patterns of drug abuse and alcohol use among homicide perpetrators and/or victims may have influenced homicide rates. Interviews with homicide offenders in prison in 1989 and 1990 found that $37 \%$ of offenders reported being under the influence of alcohol and/or illicit drugs at the time they killed their victims $(4,5)$. Other studies showed that alcohol was the substance most frequently associated with homicide before 1980, while illicit drugs, such as cocaine and heroin, were more prevalent in homicide after 1980 (6-8). In the mid 1980's autopsy results reported cocaine in approximately one-third of homicide victims, often with opiates and alcohol (9-13). Other sources determined that the prevalence of drug use among homicide decedents was higher than the prevalence of drug use in the general population (14). Therefore, patterns of population drug use may be determinants of overall homicide trends.

\footnotetext{
${ }^{1}$ Department of Psychiatry, Weill Medical College of Cornell University, New York, NY.

${ }^{2}$ Center for Urban Epidemiologic Studies, New York Academy of Medicine, New York, NY.

${ }^{3}$ Department of Epidemiology, Columbia University Mailman School of Public Health, New York, NY.

* This work was partly funded by grants DA-06534 and DA-12801-S1 from the National Institute on Drug Abuse.

Received 16 July 2004; and in revised form 1 Oct. 2004; accepted 16 Oct. 2004; published 2 Feb. 2005.
}

To date, two epidemiologic studies have assessed how illicit drugs and alcohol might influence the circumstances that lead to homicide. The first studied police classification of 1988 New York City homicides and found that $53 \%$ of homicides were drug-related (15). The authors developed a classification for drug-related homicides that differentiated those caused by the "pharmacologic" effect of drugs (i.e., homicides facilitated or caused by the perceptual distortions accompanying the ingestion of illicit drugs) from those related to the business of drug dealing (i.e., homicides due to territorial disputes or robbery), which they classified as either "systemic" or "economic." They found that the latter classification was responsible for $82 \%$ of the drug-related homicides in New York City in 1988. The second study applied the same classification using records from the District Attorney for homicides in New York between 1991 and 1993 and found that 29\% of homicides were drug-related and that $57 \%$ of these were due to the systemic or economic factors (16).

While these studies explored the role of drugs and alcohol in individual homicides, our understanding of how changes in the prevalence of drug use at the population level affect trends in homicide rates remains limited. Thus far, there has been no systematic study of the relationship between changes in the prevalence of substance use in a population and the rate of homicide over time in that population. This study seeks to determine if the $72 \%$ decline in homicides between 1990 and 1998 in New York City was related to a decline in the use of cocaine, opiates, or alcohol by homicide victims. In order to assess if a decline in substance use by homicide victims reflected a decline in the use of these substances by the general population we compared trends in the rates of toxicology-positive homicide victims with the rates of toxicology-positive accident decedents. For this study, the accident victims serve as a control to represent changes in substance use by New York City's population over time.

\section{Methods}

Victims of homicides and fatal accidents in New York City from 1990 through 1998 were identified through manual review of all 
medical files at the Office of the Chief Medical Examiner of New York (OCME). The Chief Medical Examiner has been the same person from 1990 to the current time, so that the forms, classification of cases, toxicology, policies and other aspects of the OCME has remained the same over the time period covered in this study. These files contain the victim's demographics (e.g., age, gender, and race/ethnicity), manner and cause of death, place of death and toxicology. Since the OCME is responsible for assessing all deaths of persons believed to have died in an unnatural manner, all homicides and fatal accidents (e.g., poisonings, firearm deaths, stabbings, electrocutions, explosions, and environmental exposures) in NYC would have been reviewed by the OCME and included in our data. We excluded accidental fatal drug overdoses and victims who were younger than 15 years of age or older than 65 years of age from the control sample. The former were excluded so as not to bias the accident control sample toxicology results through inclusion of persons for whom drugs might have been the primary cause of their death, and the latter were excluded to limit the persons in whom accidental death may have been secondary to central nervous system deficits related to old age. Children were excluded since drug use patterns in children are not likely representative of drug use in the general population.

The substances included in this study were cocaine, opiates and alcohol, which are the substances present in over $85 \%$ of homicides and $94 \%$ of accidents. Marijuana, amphetamines, hallucinogens and volatiles were not included in this study. Blood and urine samples of all autopsied cases were obtained at autopsy and stored at $4{ }^{\circ} \mathrm{C}$ until they were assayed. In some cases in which an autopsy was not performed, specimens were still submitted for toxicological analysis. A homogenous enzyme immunoassay of urine samples screened for benzoylecgonine, the principal metabolite of cocaine. Positive results $(\geq 0.3 \mathrm{mg} / \mathrm{L})$ from urine samples were substantiated in tests of blood samples by radioimmunoassay. If urine samples were not readily available at autopsy, benzoylecgonine was screened for in blood by radioimmunoassay; samples were considered positive if the concentration of benzoylecgonine was $\geq 0.1 \mathrm{mg} / \mathrm{L}$ and substantiated by radioimmunoassay in another tissue. A positive result suggests that cocaine could have been used up to two days before death. A gas chromatographer involving a nitrogen-phosphorus detector screened for cocaine in blood. A specimen was considered positive if the concentration of cocaine was $\geq 0.1 \mathrm{mg} / \mathrm{L}$; all samples considered positive were analyzed by gas chromatography. For the purposes of this study, specimens were considered positive for cocaine if they were positive for either cocaine or benzoylecgonine.

Initial alcohol screening was done on blood and analysis was performed by head space gas chromatography using a flame ionization detector. A specimen was considered positive for alcohol if the concentration was $\geq 0.01$ gram percent. Opiates were screened for in urine by enzyme immunoassay or, if urine was unavailable, by radioimmunoassay in blood; specimens that contained a concentration of $\geq 0.3 \mathrm{mg} / \mathrm{L}$ in urine or $\geq 0.1 \mathrm{mg} / \mathrm{L}$ in blood were considered positive for opiates and substantiated by radioimmunoassay in another tissue. The reader is referred to previous studies for further details on this data collection methodology and toxicological measurement of drugs (13).

Analyses were carried out on all homicides and accidental deaths that met inclusion criteria for this study. We first described relevant characteristics of homicide and accident victims in NYC between 1990 and 1998, including age, race, gender, and results from drug and alcohol toxicologic analyses. We focused our observations on the principal substances that appear in positive drug toxicology, namely cocaine, opiates, and alcohol. The three groups categorized in these analyses are not mutually exclusive, i.e., a decedent can have positive toxicology for one or more of these substances at the same time.

We calculated the homicide and accident death rates in New York City between 1990-1998, stratified by age, race and gender, as well as the rates of homicide and accidental deaths with positive drug and alcohol toxicology. All population denominators for rate determination were obtained from US census data (17). We obtained census population counts of NYC for 1990 and 2000 and carried out a linear interpolation of the census population counts to obtain population denominators for the intervening years. All rates were expressed per 100,000 person-years. We subsequently directly standardized overall rates for NYC by age, sex, and race to the 1990 census population for NYC to allow comparability between years relevant to this analysis and compared these rates between homicides and accidental deaths.

\section{Results}

Table 1 presents the characteristics of homicide and fatal accident victims. Victims of homicide were more likely than victims of fatal accidents to be between 15 and 34 years of age; $70.0 \%$ of homicide victims and only $41.3 \%$ of accident victims fell in that range. Victims of homicides were more likely to be AfricanAmerican or Latino ( $86.7 \%$ for homicide victims vs. $59.0 \%$ for accident victims), and male (87.5\% for homicide victims vs. $79.1 \%$ for accidents victims). Homicide victims were twice as likely as accident victims to be positive for cocaine but there was no significant difference in the proportion of homicide and accidental deaths positive for opiates or alcohol.

TABLE 1-Demographic characteristics of homicide and accident deaths, New York City 1990-1998.

\begin{tabular}{|c|c|c|c|c|}
\hline & $\begin{array}{c}\text { Homicide } \\
\mathrm{N}\end{array}$ & $\begin{array}{c}\text { Deaths } \\
\%\end{array}$ & $\begin{array}{c}\text { Accident } \\
\mathrm{N}\end{array}$ & $\begin{array}{c}\text { Deaths } \\
\% \\
\end{array}$ \\
\hline Total & 12573 & 100.0 & 6351 & 100.0 \\
\hline \multicolumn{5}{|l|}{ Age } \\
\hline $15-24$ & 4424 & 35.2 & 1165 & 18.3 \\
\hline $25-34$ & 4374 & 34.8 & 1461 & 23.0 \\
\hline $35-44$ & 2273 & 18.1 & 1429 & 22.5 \\
\hline $45-54$ & 1055 & 8.4 & 1211 & 19.1 \\
\hline $55-64$ & 447 & 3.6 & 1085 & 17.1 \\
\hline \multicolumn{5}{|l|}{ Race } \\
\hline White & 1173 & 9.3 & 2174 & 34.2 \\
\hline Black & 6258 & 49.8 & 2029 & 31.9 \\
\hline Hispanic & 4635 & 36.9 & 1715 & 27.0 \\
\hline Other & 507 & 4.0 & 433 & 6.8 \\
\hline \multicolumn{5}{|l|}{ Gender } \\
\hline Male & 10998 & 87.5 & 5024 & 79.1 \\
\hline Female & 1575 & 12.5 & 1327 & 20.9 \\
\hline \multicolumn{5}{|l|}{ Borough of Death } \\
\hline Manhattan & 2741 & 21.8 & 1793 & 28.2 \\
\hline Bronx & 3349 & 26.6 & 1118 & 17.6 \\
\hline Brooklyn & 4293 & 34.1 & 1545 & 24.3 \\
\hline Queens & 1969 & 15.7 & 1587 & 25.0 \\
\hline Staten Island & 221 & 1.8 & 308 & 4.8 \\
\hline \multicolumn{5}{|l|}{ Place of Death } \\
\hline Residence & 3349 & 27.5 & 1443 & 22.9 \\
\hline Other inside & 2454 & 20.1 & 2578 & 40.9 \\
\hline Outside & 6390 & 52.4 & 2286 & 36.2 \\
\hline \multicolumn{5}{|l|}{ Drug Use } \\
\hline Any drug & 7361 & 58.5 & 2933 & 46.2 \\
\hline Cocaine, opiates, or alcohol & 6255 & 49.7 & 2745 & 43.2 \\
\hline Cocaine & 3456 & 27.5 & 904 & 14.2 \\
\hline Opiates & 1331 & 10.6 & 727 & 11.4 \\
\hline Cannabis & 2327 & 18.5 & 395 & 6.2 \\
\hline Alcohol & 3775 & 30.0 & 1846 & 29.1 \\
\hline
\end{tabular}




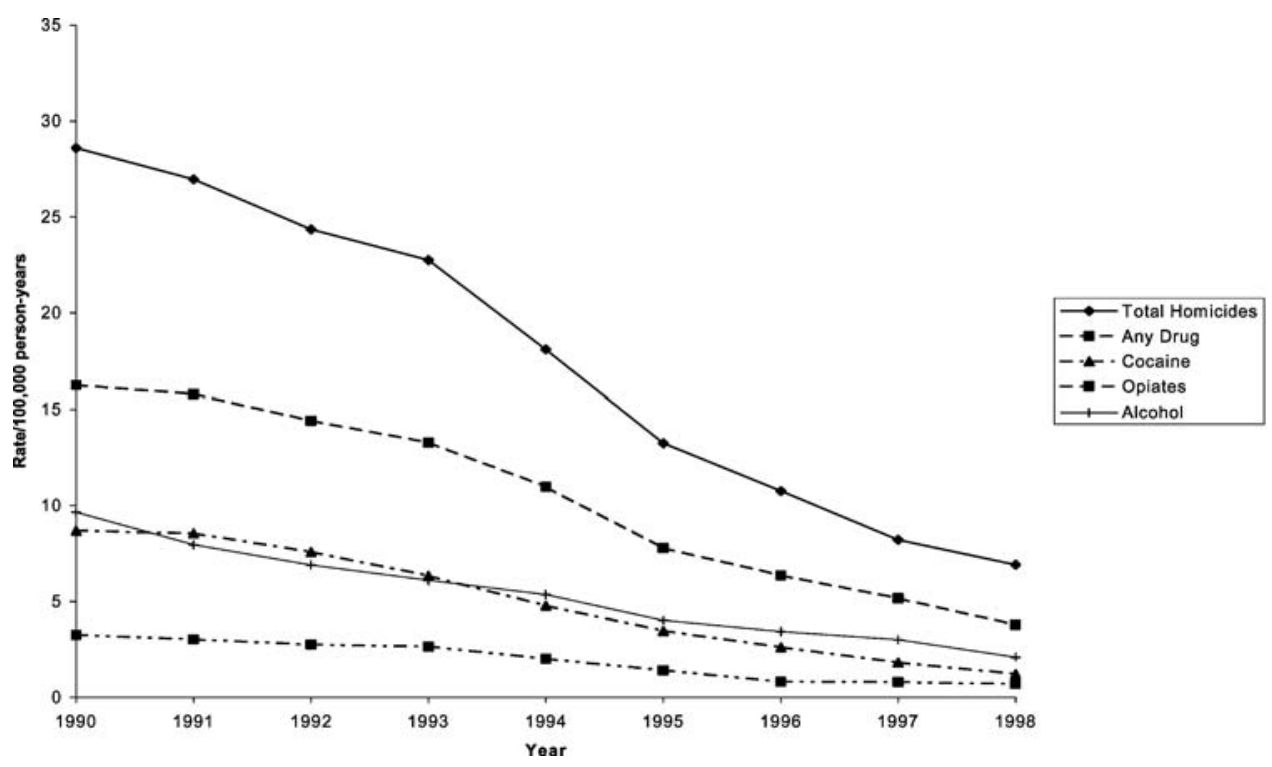

FIG. 1-Standardized Homicide Death Rates with Drugs Detected, New York City 1990-1998.

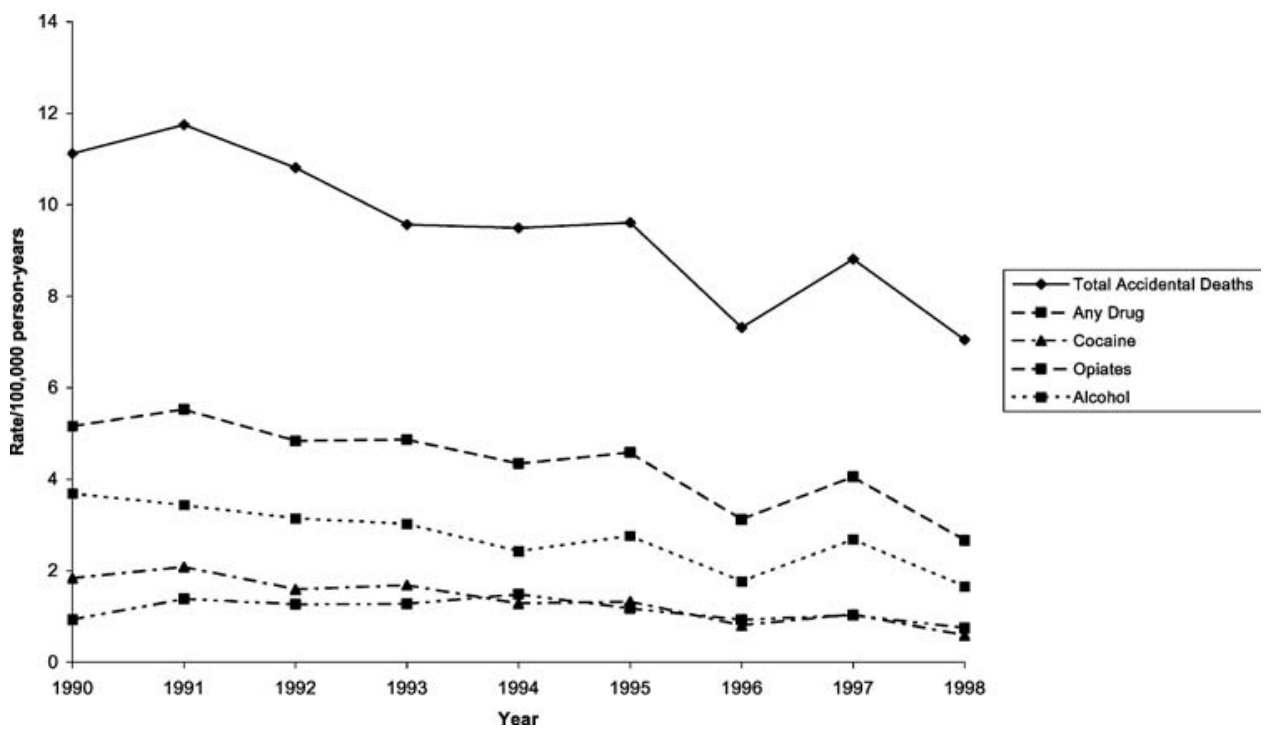

FIG. 2-Standardized Accident Death Rates with Drugs Detected, New York City 1990-1998.

Figure 1 shows the declining homicide rates and Fig. 2 shows the declining rates of accidental deaths in New York City between 1990 and 1998. The overall homicide death rate decreased from 11.12 per 100,000 in 1990 to 7.05 per 100,000 in 1998 . The rate of cocainepositive homicides fell from 8.69 per 100,000 in 1990 to 1.22 per 100,000 in 1998. The rate of cocaine-positive accidents was lower than cocaine-positive homicides in 1990 at 1.84 per 100,000 and decreased slightly to 0.59 per 100,000 in 1998 . The rate of opiatepositive homicides fell from 3.26 per 100,000 in 1990 to 0.70 per 100,000 in 1998. The rate of opiate-positive accident deaths also dropped, but within a very narrow range, from 0.93 per 100,000 in 1990 to 0.75 per 100,000 in 1998 . The rate of alcohol-positive homicides fell from 9.66 per 100,000 in 1990 to 2.10 per 100,000 in 1998. The rate of alcohol-positive accidents also declined, but from 3.69 per 100,000 in 1990 to 1.66 per 100,000 in 1998 .

The proportions of standardized homicide rates involving cocaine, opiates, and/or alcohol (rate of drug positive homicides/rate of all homicides) are presented in Fig. 3. The proportion of homicide decedents positive for cocaine fell from $30 \%$ in 1990 to $17 \%$ in 1998. $(\mathrm{t}=-7.71, \mathrm{df}=1, \mathrm{p}=0.0001)$ The proportion of homicides positive for opiates and alcohol did not change significantly in that time period. $(\mathrm{t}=-2.26, \mathrm{df}=1, \mathrm{p}=0.06 ; \mathrm{t}=0.77, \mathrm{df}=1$, $\mathrm{p}=0.47$, respectively) The proportion of accident rates positive for cocaine, opiates and/or alcohol are presented in Fig. 4. The proportion of accidents involving cocaine fell from $18 \%$ in 1990 to $9 \%$ in $1998,(t=-5.19, \mathrm{df}=1, \mathrm{p}=0.001)$ while proportions of accidents positive for opiates and alcohol did not change significantly during the same period $(\mathrm{t}=0.59, \mathrm{df}=1, \mathrm{p}=0.57 ; \mathrm{y}=-2.27, \mathrm{df}=1$, $\mathrm{p}=0.06$, respectively).

\section{Discussion}

Our study of homicide and accident death rates in New York City between 1990 and 1998 demonstrates that cocaine-, opiate-, and alcohol- positive homicide rates declined from 1990 to 1998. However, there was a comparable decline in drug-positive accident rates during the same time period and limited evidence of a decline in the proportions of homicides and accidents who were positive for 


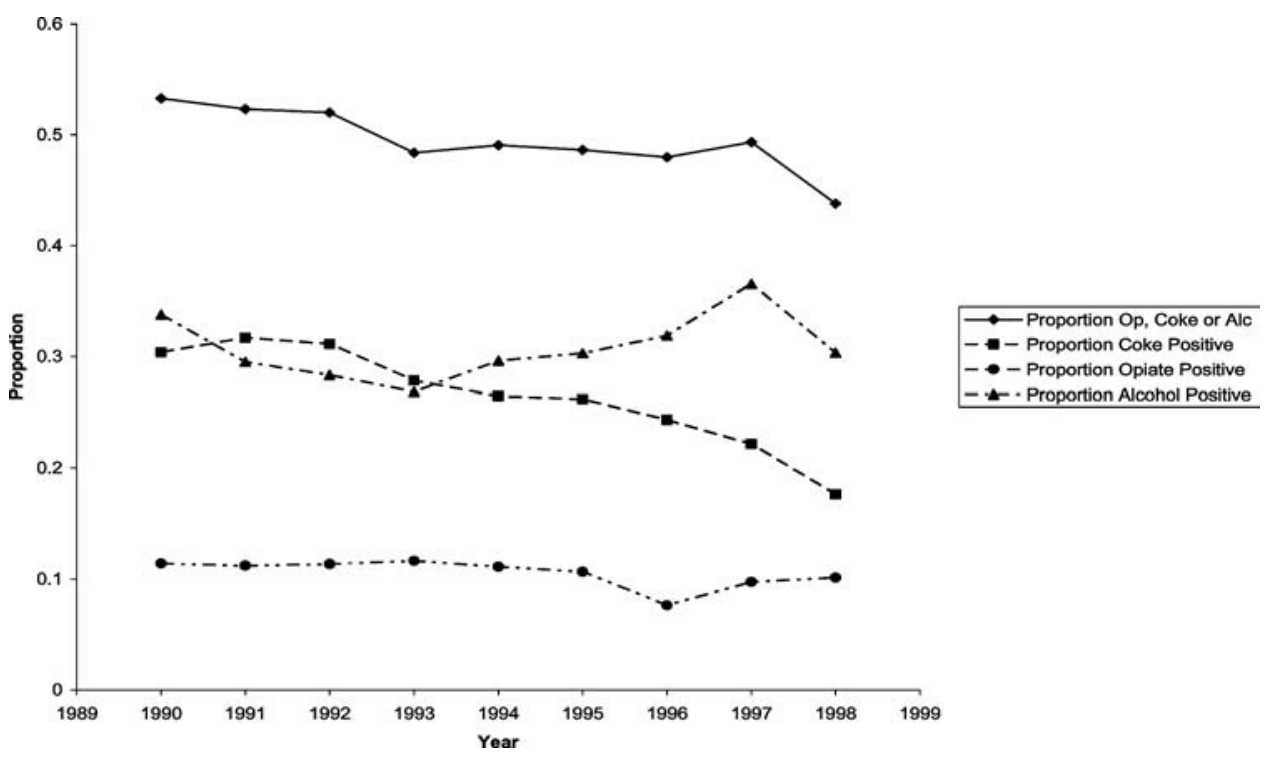

FIG. 3-Proportions of Standardized Homicide Rates with Drugs Detected, New York City 1990-1998.

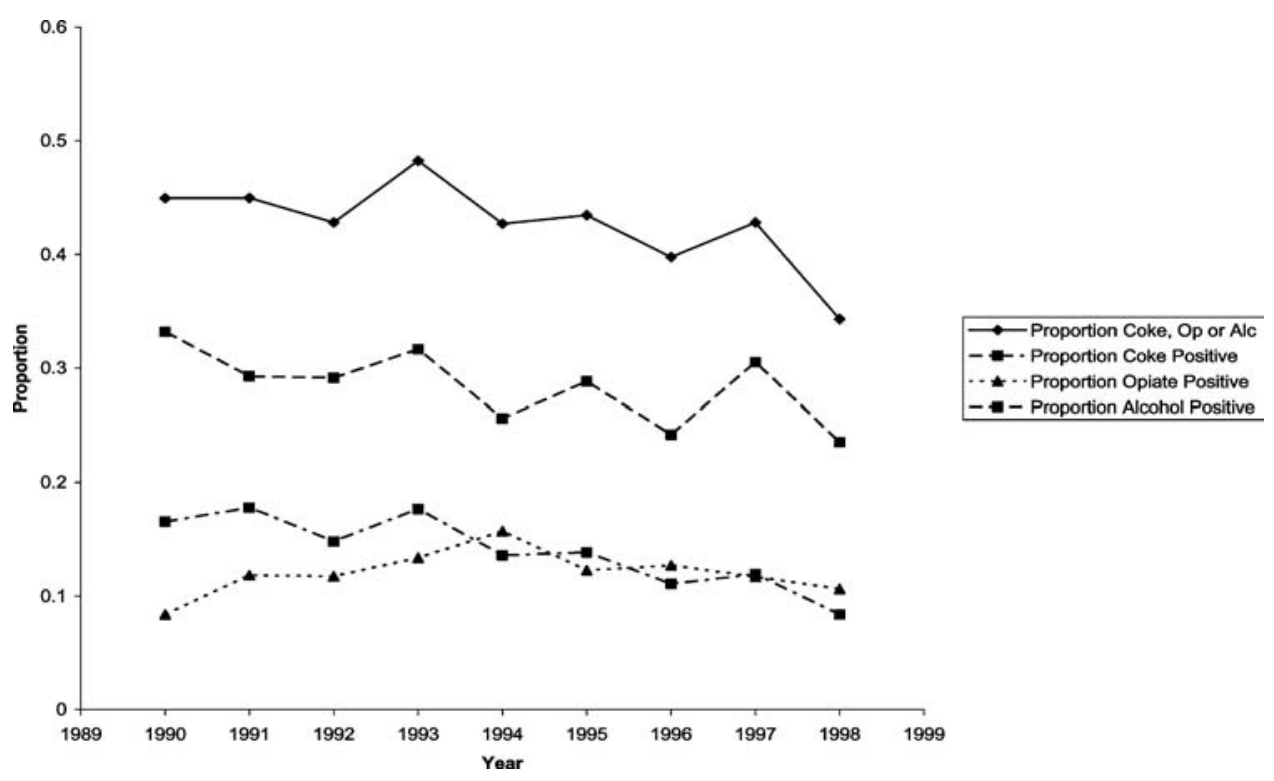

FIG. 4-Proportions of Standardized Accident Rates with Drugs Detected, New York City 1990-1998.

drugs or alcohol during this time interval. The comparability in the changing patterns of drug toxicology in homicide and accident victims suggests that changes in drug use patterns among homicide victims are unlikely to explain the decline in homicide rates in New York City during the 1990s. The presence of cocaine and opiates was much higher among victims of homicide than victims of accidents. This is consistent with previous studies that have found that homicide victims often were involved in drug use and/or drug dealing around the time they were murdered $(15,16)$.

A number of factors may have contributed to the decline in overall drug use by homicide and accident victims. These could include revitalized policing strategies, changing drug trades, and greater community involvement in crime-reduction strategies.

Revitalized police strategies implemented by the New York Police Department (NYPD) in the early 1990s improved policing and shifted the NYPD from a predominantly emergency-response force to an active model of community policing, with more police on local street patrol and a general increase in preemptive policing activity (18-22). In keeping with the "fixing broken windows" theory of crime prevention, arrests were encouraged for minor crimes such as drinking on the streets and disorderly conduct as well as for drug-dealing and other serious crimes (23). The reduction in New York City drug traffic during the 1990s has been attributed to greater NYPD efforts (22).

Crack's decreasing popularity due to a growing recognition of its dangers also may have contributed to the declining drug-positive homicide rate during the decade $(24,25)$. The crack market had been associated with more violence than other drugs and its pharmacological effects, such as irritability and paranoid thinking, increased the risk of violence $(25,26)$. Furthermore, in the mid 1990s, cocaine's less attractive pharmacological effects (i.e., the brevity of its physical effects) made it less popular than heroin and marijuana among drug users (23).

Community activities organized by New York City and neighborhood activists in response to drug abuse, homicide, and other neighborhood crime may also have contributed to the overall decrease in 
drug use and drug-positive homicide and accident victims. These activities included after-school programs for younger community members, citizen patrols, and abandoned site clean-ups (22).

However, the consistent proportion of drug-positive homicides and accidents suggests that it is unlikely that the overall decrease in homicides is attributable to a decrease in the use of drugs. Rather, this suggests that a fixed proportion of all homicides (and accidents) are in persons who use drugs, reflecting a "baseline" number of persons in any given population who use drugs and are likely to be victims of homicide or accidents.

The primary limitation of our analysis is that medical examiner data is limited to homicide victims and, as such, we cannot draw inference about drug use by perpetrators. Changing drug use by homicide perpetrators, or changing drug-related circumstances of homicide, may better explain changing patterns of homicide during the 1990s, but further studies are needed to explore the merits of this argument (27).

In conclusion, data from New York City homicide and accidental death victims suggests that changing drug and alcohol use by the homicide victims was not a primary determining factor of the decline in homicide rates between 1990 and 1998. Further work, is needed to further explore how other factors may have contributed to declining homicide rates.

\section{References}

1. Helmuth L. Has America's tide of violence receded for good? Science 2000;289:582-5.

2. Federal Bureau of Investigation. Crime in the United States: Annual Uniform Crime Reports. Washington (DC): Department of Justice, 19901999.

3. Cyrus S, Guahua L. Homicide mortality in the US, 1935-1994: Age, period, and cohort effects. Am J Epidemiol 1999;150:1213-22.

4. Spunt B, Goldstein P, Brownstein H, Fendrich M, and Langley S. Alcohol and homicide: Interviews with prison inmates. J Drug Issues 1994;24:143-63.

5. Spunt B, Brownstein H, Goldstein P, Fendrich M, Liberty HJ. Drug use by homicide offenders. J Psychoactive Drugs 1995;27:125-34.

6. Haberman P, Baden M. Alcohol, other drugs and violent death. New York: Oxford University Press, 1978.

7. Kratcoski PC. Circumstances surrounding homicides by older offenders. Crim Justic Behav 1990;17:420-30.

8. Wieczorek WF, Welte JW, Abel EL. Alcohol, drugs and murder: A study of convicted homicide offenders. J Crim Justice 1990;18:217-27.

9. Tardiff K, Marzuk PM, Leon AC, Hirsch CS, Stajic M, Porter L, Hartwell N. Cocaine, opiates and ethanol in homicides in New York City: 1990 and 1991. J Forensic Sci 1995;40:387-90.
10. Hanzlick R, Gowitt GT. Cocaine metabolite detection in homicide victims. JAMA 1991;26:760-61.

11. Garriott JC. Drug use among homicide victims: Changing patterns. Am J Forensic Med Path 1993;14:234-37.

12. Rogers JN, Henry TE, Jones AM, Froede RC, Byers JM. Cocainerelated deaths in Prima County Arizona, 1982-1984. J Forensic Sci 1986;31:1404-8.

13. Tardiff K, Marzuk PM, Leon AC, Hirsch CS, Portera L. Homicide in New York City: Cocaine and firearms. JAMA 1994;272:43-6.

14. National Institute on Drug Abuse. National household survey on drug abuse: Main findings 1991. 1993 U.S. Dept. of Mental Health and Human Services Publication S.M.A. 93-1980.

15. Goldstein PJ, Brownstein HH, Ryan PJ, Bellucci PA. Crack and homicide in New York City, 1988: A conceptually based event analysis. Contemp Drug Problems 1989;16:652-87.

16. Tardiff K, Marzuk PM, Lowell K, Portera L, Leon AC. A study of drug abuse and other causes of homicide in New York. J Crim Justice 2002;30:125-34.

17. Bureau of the Census. Census summary tape, file 3A (STF3A). Washington (DC): US Department of Commerce, 1990 and 2000.

18. Office of Management Analysis and Planning. The Compstat Process. New York (NY): The New York City Police Department (No. BM 754), 1997.

19. Bratton W. Crime is down in New York City: Blame the police. In: Dennis $\mathrm{N}$, editor. Zero tolerance: Policing a free society. London: Institute of Economic Affairs, 1997.

20. Bratton W, Knobler. Turnaround: How America's top cop reversed the crime epidemic. New York: Random House, 1998.

21. Gorta B. Zero tolerance-The real story or the hidden lessons of New York. Police Research and Management 1998;Winter:15-21.

22. Bowling B. The rise and fall of New York murder. Brit J Criminol 1999;39:531-54.

23. Kelling GL, Coles CM. Fixing broken windows: Restoring order and reducing crime in our communities. New York: Simon and Schuster, 1996.

24. Hamid A. The developmental cycle of a drug epidemic: The cocaine smoking epidemic of 1981-1991. J Psychoactive Drugs 1992;4:337-48.

25. Golub A, Johnson B. A recent decline in cocaine use among youthful arrestees in Manhattan, 1987 through 1993. Am J Public Health 1994;84:1250-4.24.

26. Manschreck TC, Laughery J, Weisstein CC, Allen D, Humblestone B, Neville M, Podlewski H, Mitra N. Characteristics of freebase cocaine psychosis. Yale J Biol Med 1988;61:115-22.

27. Blumstein A, Rivara FP, Rosenfeld R. The rise and decline of homicideand why. Annu Rev Public Health 2000;21:505-41.

[PubMed]

Additional information and reprint requests:

Kenneth Tardiff, M.D., M.P.H

Department of Psychiatry Box 140

Weill Cornell Medical College

525 East 68th Street

New York, New York 10021 